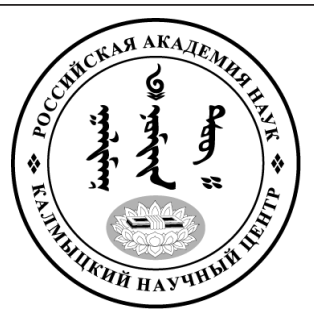

Published in the Russian Federation

Oriental Studies (Previous Name: Bulletin of the Kalmyk Institute

for Humanities of the Russian Academy of Sciences)

Has been issued as a journal since 2008

ISSN: 2619-0990; E-ISSN: 2619-1008

Is. 5, pp. 966-973, 2019

DOI: $10.22162 / 2619-0990-2019-45-5-966-973$

Journal homepage: https://kigiran.elpub.ru

УДК 811.512

\title{
Социативная каузация в бурятском языке
}

\author{
Елена Александровна Дадуева ${ }^{1}$, Дарима Шагдуровна Харанутова ${ }^{2}$ \\ ${ }^{1}$ Бурятский институт инфокоммуникаций Сибирского государственного университета телеком- \\ муникаций и информатики в г. Улан-Удэ (д. 152, ул. Трубачеева, 670031 Улан-Удэ, Российская \\ Федерация) \\ кандидат филологических наук, доцент кафедры \\ ORCID: 0000-0002-2562-7331.E-mail: edadueva@yandex.ru
}

${ }^{2}$ Бурятский государственный университет (д. 24, ул. Смолина, 670000 Улан-Удэ, Российская Федерация)

доктор филологических наук, доцент

ORCID: 0000-0001-5692-5393. E-mail: dkharanutova@mail.ru

Аннотация. Введение. В работе поднимаются проблемы семантики и функционирования социативного каузатива в бурятском языке. При социативной каузации наблюдается совмещенность каузирующей и каузируемой ситуации в пространстве и времени, при этом каузируемый объект наделен волей и может контролировать процесс. Основной целью работы является выявление особенностей функционирования социативного каузатива в бурятском языке, в котором данная проблема ранее не рассматривалась. Материаль и методы. Материалом исследования послужили примеры из художественных произведений, размещенных в Электронном корпусе бурятского языка. Использованы методы контекстного и дистрибутивного анализа. Результа$m b l$. В соответствии с континуальной шкалой семантических типов каузации в бурятском языке правомочно выделение трех значений социативной каузации: «совместное действие» (joint action), «ассистив» (assistive) и «надзор» (supervision). В работе отмечается, что социативный каузатив в бурятском языке меняет событийную и ролевую структуру каузативной конструкции. Исследование показало, что особенностью ролевой структуры совместного действия является то, что каузатор и каузируемый объект выполняют одни и те же или похожие действия, при ассистиве место каузатора занимает помощник, каузатор здесь получает роль дополнения, надзор же предполагает смену роли каузатора на роль наблюдателя. Установлено, что социативность в бурятском языке связана с семантикой совместного и взаимного залогов. Рассмотрены особенности конструкций с разной семантикой социативного каузатива. Выявлено, что наиболее частотно выражение значения совместного действия посредством конструкций с совместным падежом, а ассистивности - конструкциями с дательным падежом. Значение надзора реализуется в основном в полипредикативных конструкциях.

Ключевые слова: каузативность, каузативный глагол, социативная каузация, совместное действие, ассистивность, прямая каузация, непрямая каузация, категория залога

Для цитирования: Дадуева Е. А., Харанутова Д. Ш. Социативная каузация в бурятском языке. Oriental Studies. 2019;(5): 966-973 DOI: 10.22162/2619-0990-2019-45-5-966-973. 
UDC 811.512

\title{
Sociative Causation in the Buryat Language
}

\author{
Elena A. Dadueva', Darima Sh. Kharanutova ${ }^{2}$ \\ ${ }^{1}$ Buryat Institute of Infocommunications, Siberian State University of Telecommunications and \\ Information Sciences (152, Trubacheev St., Ulan-Ude 670031, Russian Federation); \\ Cand. Sc. (Philology), Associate Professor \\ ORCID-0000-0002-2562-7331.E-mail: edadueva@yandex.ru \\ ${ }^{2}$ Buryat State University (24, Smolin St, Ulan-Ude 670000, Russian Federation) \\ Dr. Sc. (Philology), Associate Professor \\ E-mail: dkharanutova@mail.ru
}

\begin{abstract}
Introduction. The paper deals with semantics and functioning of the sociative causative in the Buryat language. Sociative causation implies a combination of the causing and caused situations in space and time, the caused object being endowed with will and able to control the process. Goals. The study primarily seeks to identify functioning features of the Buryat sociative causative, since the aspect has not been duly examined yet. Materials and Methods. The work analyzes fiction texts included in the online Buryat Corpus, employs the methods of contextual and distributive analysis. Results. The paper notes that the sociative causative changes the event and role structures of the causative construction. According to the continual scale of semantic types of causation, three meanings of sociative causation can be distinguished in the Buryat language, namely: 'joint action', 'assistive' and 'supervision'. The study shows that the role structure of joint actions is characterized by that both the causator and object of causation perform same or similar actions, in assistive patterns an assistant replaces the causator and the latter here takes on the role of complement, supervision also implies that the causator turns into an observer. It is concluded that sociativeness in the Buryat language is associated with semantics of active and passive voices. Special attention is paid to constructions with different semantics of the sociative causative. The work reveals the meaning of joint action is most frequently expressed by means of joint case constructions, and that of assistivity by dative case ones. The meaning of supervision is basically manifested through poly-predicative constructions.

Keywords: causativity, causative verb, sociative causation, joint action, assistive, direct causation, indirect causation, category of voice

For citation: Dadueva E. A., Kharanutova D. Sh. Sociative Causation in the Buryat Language. Oriental Studies. 2019;(5): 966-973 DOI: 10.22162/2619-0990-2019-45-5-966-973.
\end{abstract}

\section{है}

\section{Введение}

В современных исследованиях по актантной деривации активно обсуждается проблема семантических и синтаксических коррелятов широко засвидетельствованного противопоставления контактных (прямых) и дистантных (непрямых, опосредованных) каузативов [Недялков 1964; Недялков, Сильницкий 1969; Иванов 2008] и др.

М. Шибатани и П. Пардеши предлагают вместо традиционной двучленной пары контактных и дистантных каузативов континуальную шкалу семантических типов каузации. На противоположных сторонах этой шкалы лежат прямая и непрямая ка- узация, а между ними находится третий тип - социативная каузация: прямая каузациия $\rightarrow$ совместное действие $\rightarrow$ ассистив $\rightarrow$ надзор $\rightarrow$ непрямая каузация. Социативная каузация охватывает промежуточные типы каузативов: «совместное действие» (joint action), «ассистив» (assistive) и «надзор» (supervision) [Shibatani, Pardeshi 2002: 90]. Итак, промежуточные типы представляют три разновидности социативной каузации.

В данной работе мы рассмотрим выделенные семантические разновидности социативного каузатива на материале бурятского языка в соответствии с континуальной шкалой, которая позволит более тщательно 
описать семантические изменения при переходе от прямой каузации к непрямой каузации.

В целом, согласно М. Шибатани и П. Пардеши, социативный каузатив, отличаясь от прямой и непрямой каузации, обладает признаками обоих типов. Например, при социативной каузации, как и при прямой каузации, наблюдается признак совмещенности в пространстве и во времени каузирующей и каузируемой ситуации. Например: Би эжытэеэ үнеэ һаалсанаб ' $Я$ с мамой дою корову' - Үнеэн һаагдажа байна 'Корова доится' ${ }^{\prime}$, т. е. оба события происходят в одно время и в одном месте. С непрямой каузацией социативную каузацию сближает то, что второй участник (мама), выраженный дополнением, наделен волей и может контролировать процесс. Заметим, что для выделения всех семантических типов социативной каузации учитывается роль каузатора в каузируемой ситуации.

При раздельном рассмотрении каждого типа социативной каузации проявляются различия в их отношении к прямой и непрямой (опосредованной) каузации. Первые две разновидности по континуальной шкале («совместное действие» и «ассистив») близки к прямой каузации тем, что каузатор непосредственно принимает участие в каузируемом действии. Но при совместном действии каузатор и каузируемый объект совершают одинаковые действия, а при ассистивной каузации один участник помогает другому участнику в осуществлении каузируемого действия. Ср: Би ухибуугээ эмшэндэ абаашааб 'Я повел ребенка к врачу' (совместное действие), Би эмиэндэ ошоходонь, эжылээ туһалааб ' $Я$ помог бабушке добраться до врача' (ассистив). Третья разновидность «надзор» характеризуется тем, что каузатор только осуществляет контроль за каузируемым объектом. Например: Эжынь ном уншана гу гэжэ ухибуугээ анхарна 'Мать следит, чтобы ребенок читал книгу’.

Основной целью работы является выявление особенностей функционирования социативного каузатива в бурятском языке, в котором данная проблема ранее не рассматривалась. В задачи исследования входит: 1) выделение в бурятском языке трех зна-

1 Здесь и далее предложены личные примеры авторов, а также дан перевод на русский язык авторов статьи. чений социативной каузации и определение критериев их разграничения; 2) определение событийно-ролевой структуры социативных каузативных конструкций; 3) определение грамматических особенностей социативного каузатива.

\section{Основная часть}

Каковы же особенности социативной каузации в бурятском языке?

Для начала рассмотрим примеры социативной каузации со значением совместного действия и ассистива в бурятском языке.

C точки зрения каузативной проблематики интерес представляют глаголы совместного и взаимного залогов, основными средствами выражения которых являются аффиксы -лса, -лда. Данные залоги используются в комитативных конструкциях для обозначения действий, производимых «многими, так сказать, на коллективных началах» [Санжеев 1963: 60], из них совместный залог «показывает соучастие двух или более лиц в каком-либо одном действии» [Санжеев 1963: 57]. Например, у глагола табилсаха '1) ставить вместе с кем-либо; 2) помогать кому-либо ставить', образованного от глагола табиха 'ставить' при помощи словообразовательного суффикса -лса, в первом значении реализуется сема совместного действия, а во втором - ассистивности.

Значения глаголов совместного и взаимного залогов тесно связаны с семантикой социативной каузации. Как верно отмечает Г. Д. Санжеев, «при разборе значений залога в монгольских языках необходимо следить за поведением двух компонентов: первого, обозначенного подлежащим, и второго, выраженного в косвенном дополнении. В обороте совместного залога второй компонент производит какое-либо действие, а первый лишь присоединяется ко второму для совместного совершения этого действия» [Санжеев 1963: 57].

Заметим, это определение сходно с определением ассистива, который является одним из основных разновидностей социативного каузатива. При ассистиве добавляется участник-помощник, который, хотя и выражен подлежащим, не является инициатором действия, а выполняет функцию помощника. В ассистивной конструкции второй компонент, указанный Г. Д. Санжеевым, представляет агенса, который и выпол- 
няет действие. Как видим, данное определение соответствует нашему утверждению, что ассистив в бурятском языке выражается при помощи совместного залога.

(1) Эжы-нгээ уг-өөр табаг таби-лса-на, сай аягала-лса-на Мать-GEN слово-INS посуда ставить-SOC.CAUS-PRS, чай наливать-SOC.CAUSPRS.3Sg

'По приказу мамы помогает расставлять посуду, наливать чай'

[ЭКБЯ 2012. С. Норжимаев. Гурбан һогоон].

Также обратим внимание на то, что морфологическими показателями конструкций совместного действия и ассистива могут выступать суффиксы совместного залога -лса, взаимного - -лда. Давно подмечено, что функции совместного и взаимного залогов часто пересекаются [Санжеев 1960: 65].

Кстати, в бурятских словарях часто отмечается тождественное значение слов с данными аффиксами. Например, так выглядит перекличка суффиксов взаимного залога -лса и -лда: бари-лда-ха 'взаимн. от бариха 1) хватать друг друга, бороться, состязаться в борьбе <...>' и бари-лса-ха 'взаимн. от бариха 1) держать, хватать (или ловить) друг друга' [БРС 2006: 118]. К слову, во многих языках мира, например, в тюркских языках, значение социативной каузации обычно также выражается реципрокной морфемой [Абдиев 2009: 68].

Однако следует заметить, что границы данных залогов и социативной каузации не всегда совпадают. Так, глаголы традиционного совместного и взаимного залогов начинают выполнять функции социативного каузатива при определенных условиях. Главным критерием, без сомнения, является семантический критерий. Социативные каузативы - это каузативные глаголы, т. е. глаголы, выражающие воздействие на определенные каузируемые объекты с целью вызвать ответные действия или состояния, выполняемые совместно двумя или более лицами. По нашему мнению, в круг социативных каузативов не включаются такие глаголы взаимного залога, как, например: тэбэрилдэхэ 'обниматься', талалдаха 'нежиться, обниматься' и т. п., которые не имеют значение каузативного воздействия, а лишь выражают взаимно-направленные действия, не предполагающие в результате определенные каузированные действия или состояния. Такие собственно комитативные конструкции вводят двух участников с одинаковыми ролями. Например:

\section{(2) Удаань дахин тэбэри-лдэ-бэ, ахин тала-лда-ба}

Долго опять обниматься-SOC-PST.3, опять целоваться-SOC-PST.3

'Опять долго обнимаются, снова целуются'

[ЭКБЯ 2012. Ж. Тумунов. Нойрһоо һэриһэн тала].

Такие конструкции с глаголами взаимного залога мы не относим к каузативным конструкциям, так как каузативная семантика здесь отсутствует. Невозможно предположить, что в ситуации, когда кто-либо целуется или обнимается, один участник оказывает воздействие на другого участника с определенной целью. Такие действия являются взаимными, и ни один из участников ситуации не провоцирует другого на ответное действие или состояние. Семантические роли обоих субъектов одинаковые и не направлены на другие объекты, а в каузативной конструкции всегда существуют участники, действия которых производятся либо совместно и направлены на каузируемые объекты, либо один участник оказывает помощь другому в совершении действия. Ср.: хубаа-лда-ха 'делить между собой' социативный каузатив, обозначающий воздействие, выполняемое совместно, с целью хубааха 'делить', результатом совместного действия является каузированное состояние объекта хубаагдаха 'разделиться'. Например: Тэдэ газараа хубаа-лда-на 'Они делят землю' (совместное воздействие) $\rightarrow$ Газарынь хубаагдаба 'Земля поделена' (каузированное состояние).

Также отметим, что обязательным условием выделения социативного каузатива 
является класс производящей основы: социативные каузативы образуются только от переходных каузативных глаголов, т. е. от глаголов, обозначающих каузативные воздействия на определенные объекты с целью вызвать ответные действия или состояния. Например: нээ-хэ 'открывать что-либо' $\rightarrow$ нээ-лсэ-хэ 'совместно что-либо открывать или помогать открывать', аба-ха 'брать' $\rightarrow$ аба-лса-ха, аба-лда-ха 'брать вместе с кем-либо', ала-ха 'убить' $\rightarrow$ ала-лса-ха 'убивать сообща' и т. д.

Социативный каузатив не образуется от непереходных глаголов. Например: $y н$ ma-xa 'спать' $\rightarrow$ унта-лса-ха 'спать вместе с кем-либо', хэбтэ-хэ 'лежать' $\rightarrow$ хэбтэлсэ$x \ni$ 'лежать вместе с кем-либо' и т. п. Таким образом, переходность напрямую связана со значением каузативного воздействия.

Социативная каузация развивается только на основе каузативных конструкций, т. е. развитие идет по континуальной шкале от прямой каузации к совместному действию. В этом случае производящими основами могут служить как немаркированные, так и маркированные каузативные глаголы. Например: $x a a-x a$ 'закрывать' - каузативный немаркированный глагол, обозначающий физическое воздействие на определенный объект, т. е. на прямую каузацию. От данного глагола образуется социативный каузатив $x a a-л c a-x a$ 'закрывать вместе с кем-то, помогать закрывать', имеющий значение совместного действия. От маркированного каузативного глагола хар-уул-ха ‘показывать' (каузативный показатель -уул) возможно образование социативного каузатива хар-уула-лса-ха 'показывать вместе с кем-либо'. Например: Барга-Няма хонидыень хайшалалгын пунктын хорёодо хаалса-ба 'Барга-Няма помог закрыть овец в загоне пункта для стрижки’ [ЭКБЯ 2012. Б. Мунгонов. Баян зүрхэн - II, 1979].

Таким образом, процесс образования социативного каузатива в бурятском языке можно назвать процессом реципрокализации каузатива. Как указывает С. А. Оскольская, «реципрокальная конструкция не обязательно должна иметь значение реципрокальной ситуации, она может описывать также социативную ситуацию и ситуацию следования» [Оскольская 2009: 315]. Ср.: баярл-уул-ха 'радовать' - баярл-уу-лса-ха ‘радовать вместе с кем-либо', бод-хоо-хо ‘поднимать, строить' - бод-хоо-лсо-хо 'помогать поднимать, строить вместе с кем-либо' и т. д. В этом процессе не происходит утрата каузативного значения, только добавляется значение совместности оказываемого воздействия. Например: Ленинэй орденто оперо ба баледэй театрhаа захалаад, бэшэ олон театрнуудые, институуд, һургуулинууды бод-хоо-лсоо юм 'Начиная с театра оперы и балета ордена Ленина, он помог возвести много других театров, институт, школы' [ЭКБЯ 2012. Ц.-Ж. Жимбиев. Талын харгынууд]

Следует заметить, что очень ярко в бурятском языке представлено ассистивное значение каузации. В переводных бурятско-русских словарях чаще всего фиксируется именно это значение социативной каузации. В переводе на русский язык бурятские глаголы с суффиксом -лса уточняются при помощи глагола помогать, т. е. в русском языке ассистивность выражается посредством вершинного глагола (глагола в неопределенной форме), а в бурятском языке - маркированного глагола. Ср.: яб-уула-лса-ха 'помогать отправлять', тээ-лсэ-хэ 'помогать грузить' и т. д. Ассистив добавляет в каузативную конструкцию участника-помощника. Например: хахал-ха 'разрезать вдоль, перерубать, раскалывать' хаха-лса-ха 'помогать раскалывать дрова'. Глагол хаха-лса-ха содержит ассистивное значение. Помощник в отличие от каузатора не инициирует каузируемое действие, а только помогает его совершить. Например: Би самсаяа тайлажа угэбэб, тэрэниием угаахадань хамһалсан, бажуул-лса-наб ' $Я$ отдал рубашку и, когда ее стирали, помогал выжимать' [ЭКБЯ 2012. Ц.-Ж. Жимбиев. Талын харгынууд].

Социативная каузативная конструкция имеет особенности как в структуре самого события, так и в ролевой структуре. Каузативная ситуация, как известно, состоит из двух событий: каузирующее событие и каузируемое событие. В ролевой структуре важен участник-каузатор, который и совершает каузирующее действие. При совместном действии роли обоих участников примерно одинаковы, но стоит заметить, что роль участника, выраженного подлежащим, сводится к тому, что его действия совершаются, в большей степени, в интересах другого участника. 
(3) Тэрэ нам-тай ногоо сабша-лса-ба

Он я-СOM трава косить-SOC.CAUS-PST.3Sg

'Он косил со мной траву' (совместное действие).

Наличие социативного каузатива увеличивает количество ролей, добавляя в ассистив- ной ситуации участника-помощника, который отодвигает на второй план каузатора. Ср.:

\section{(4) Тэрэ намда ногоо сабша-лса-ба}

Он я-DAT трава косить- SOC.CAUS-PST.3Sg

‘Он помогал мне косить траву' (ассистив).

Традиционно считается, что каузатив добавляет нового участника с функцией агенса в аргументную структуру. Однако в современных теориях «каузатив трактуется как преобразование, добавляющее в структуру глагола не только аргумент с ролью Агенса или Каузатора, но и подсобытие, которое включает в себя деятельность этого аргумента и каузирует ситуацию, выраженную исходной основой» (цит. по: [Иванов 2008: 57]).

Новый участник-помощник вводится в роль каузатора, тем самым меняя событийную структуру. Каузатор же уходит на другую синтаксическую роль, роль дополнения. Каузирующее событие выполняется при помощи помощника, а каузируемое событие реализуется все-таки самим каузатором. Синтаксическое устройство предложений с разными типами социативных каузативов в бурятском языке разное, так как оно зависит от ролевой структуры.

Как видим, происходит перераспределение агентивной структуры. Так же, как и при дистантной (непрямой) каузации, действие распределено между каузатором и помощником. Помощник, занимающий позицию подлежащего, при этом не является основным исполнителем воздействия, контроль за каузируемым событием принадлежит реальному исполнителю, «зачинателю» данного события, каузатору, который оказался в каузативной конструкции в роли дополнения.

Как указывал Г. Д. Санжеев, «в совместном обороте инициатором или главным исполнителем какого-либо действия является предмет, обозначенный в особом дополнении или упомянутый в предыдущем предложении, тогда как предмет-подлежащее выступает лишь в качестве его соучастника на начальном или заключительном этапе действия» [Санжеев 1963: 239]. Помощник в бурятском языке выражается подлежащим, а каузатор, инициировавший действие, - дополнением, обычно в дательном или совместном падеже. Например:

(5)Би тэрэ хүббүн-тэй $\gamma \gamma \partial э \quad$ нээ-лсэ-бэ-б

Я тот мальчик-СОМ дверь открыть-SOC.CAUS-PST-1Sg

'Я помог мальчику открыть дверь'.

Таким образом, значение совместности в бурятском языке чаще всего выражается при помощи конструкций с совместным па-

дежом, а ассистивность - при помощи дательного падежа. Сp.:

(6)Би аба-даа түүлеэ хаха-лса-ба-б

Я отец-DAT дрова расколоть-SOC.CAUS-PST-1Sg

'Я помог отцу расколоть дрова' (ассистив).

(7)Би аба-таяа түүлеэ хаха-лса-ба-б

Я отец-СОМ дрова расколоть-SOC.CAUS-PST-1Sg

' $Я$ с отцом колол дрова' (совместное действие). 
Надзор (supervision), являющийся еще одним типом социативной каузации, в бурятском языке может выражаться при помощи полипредикативных конструкций с предикатным актантом. Так, конструкции с глаголами адаглаха 'наблюдать, следить', xapaxa 'смотреть' и предикатными актантами в форме причастия будущего времени с показателями падежа и притяжания являются одним из средств выражения значения надзора. Собственно семантика надзора выражается вершинным глаголом, а каузируемое действие - предикатным актантом. Например: Баторов урагшаа ябахынгаа урда тээ отрядайнгаа муу бэшэ газарта дайшалхы позиции эзэл-hые адагла-на 'Баторов, прежде чем идти вперед, следит, чтобы отряд занял хорошую боевую позицию’ [ЭКБЯ 2012. Б. Шойдоков. Дайсанай ара талада 1995].

В таких конструкциях ролевая структура меняется: каузатор здесь занимает позицию наблюдателя или надзирателя, при этом он не совершает никаких действий (не помогает, как при ассистиве, не выполняет похожих действий, как при совместном действии). Каузируемое событие достигается самим каузируемым объектом, но при непосредственном наблюдении каузатора. Семантика надзора наиболее близка в семантическом континууме каузативности к непрямой каузации. Например, в ситуации Эжынь хубуундээ ном уншуулха гэж анхаралаа табина 'Мать следит за тем, чтобы сын читал' можно увидеть ситуацию, что Мать не просто следит, а заставляет сына читать: Мать заставила сына читать и следит за тем, чтобы он читал. Ср.: Эжынь Бадмые номоо уншахыень хараад байна 'Мать следит за Бадмой, чтобы он читал' (каузирует сына читать).

\section{Источники}

ЭКБЯ 2012 - Бурятский корпус (электронный корпус бурятского языка) [электронный ресурс] // URL: http://web-corpora.net/ BuryatCorpus/search/?interface_language $=\mathrm{ru}$ (дата обращения: 29.08.2019).

\section{Sources}

Online Buryat Corpus. An Internet resource: http://web-corpora.net/BuryatCorpus/ search/?interface_language $=\mathrm{ru}$ (accessed: August 29, 2019). (In Bur.)

\section{Выводы}

Итак, социативные каузативы - это каузативные глаголы, выражающие воздействия на определенные каузируемые объекты с целью вызвать ответные действия или состояния. Такие воздействия могут выполняться либо совместно двумя или более лицами, либо при помощи каузаторов, либо под их надзором. Таким образом, в бурятском языке социативные каузативы со значением совместного действия и ассистива тесно связаны со значениями совместного и взаимного залогов. Социативный каузатив в бурятском языке образуется только от переходных каузативных глаголов при помощи суффиксов -лса и -лда.

Социативная каузация в бурятском языке выражается чаще всего в двух значениях: совместное действие и ассистив. В таких социативных каузативных конструкциях можно выделить несколько компонентов: каузатор, каузируемый объект, субъект-помощник и каузируемое действие, выраженное социативным каузативом. Такая каузативная конструкция меняет событийно-ролевую структуру каузативной ситуации. Социативный каузатив может добавлять в каузативную конструкцию участника-помощника, который в бурятском языке выражается подлежащим, а каузатор, инициировавший действие, - дополнением, обычно в дательном падеже. Значение совместного действия здесь чаще всего выражается посредством конструкций с совместным падежом. Реже встречаются в бурятском языке конструкции со значением надзора, который выражается в основном в полипредикативных конструкциях с вершинным глаголом в сочетании с предикатными актантами - причастиями будущего времени. В этом случае каузируемое действие выражается предикатным актантом.

\section{Абдиев $2009-$ Абдиев $T$. Конструкции с кау- зативными глаголами в киргизском языке. Бишкек: Изд-во Кыргызско-турецкого ун-та «Манас», 2009. 14 с.}

БРС 2006 - Бурятско-русский словарь / Л. Д. Шагдаров, К. М. Черемисов. Улан-Удэ: Респ. тип., 2006. Т. 1. 636 с.

Иванов 2008 - Иванов М. Ю. Каузативизация и предельность // Исследования по глагольной деривации: Сб. ст. / отв. ред. В. А. Плунгян, 
С. Г. Татевосов. М.: Языки славянских культур, 2008. С.47-72.

Недялков 1964 - Недялков В. П. О связи каузативности и пассивности // Уч. зап. Башкирского гос. ун-та, XXI, серия филол. наук. 1964. № 9. С. 301-310.

Недялков 1969 - Недялков В. П., Сильницкий Г. Г. Типология морфологического и лексического каузативов // Типология каузативных конструкций. Л.: Наука, 1969. 311 с

Оскольская $2009-$ Оскольская С. А. О глагольных показателях множественности участников в калмыцком языке // Acta Linguistica Petropolitana. Труды института лингвистических исследований. 2009. Т. 5. № 2. С. 310-346.

Санжеев 1960 - Санжеев Г. Д. Современный монгольский язык. М.: Вост лит., 1960. $104 \mathrm{c}$.

Санжеев 1963 - Санжеев Г. Д. Сравнительная грамматика монгольских языков. Глагол. М.: Наука, 1963. 266 с.

Shibatani, Pardeshi 2002 - Shibatani M., Pardeshi $P$. The causative continuum // The Grammar of Causation and Interpersonal Manipulation [Typological Studies in Language]. Vol. 48. Masayoshi Shibatani (ed.), Amsterdam: John Benjamins, 2002. Pp. 85-126.

\section{References}

[Buryat-Russian Dictionary]. L. D. Shagdarov, K. M. Cheremisov (comps.). Ulan-Ude:
Respublikanskaya Tipografiya, 2006. Vol. 1. 636 p. (In Bur. and Russ.)

Abdiev T. [Kyrgyz Causative Verb Constructions]. Bishkek: Kyrgyz-Turkish Manas University, 2009. 14 p. (In Russ.)

Ivanov M. Yu. Causativization and boundedness. In: [Investigating Verb Derivation]. Coll. papers. V. A. Plungyan, S. G. Tatevosov (eds.). Moscow: Yazyki Slavyanskikh Kultur, 2008. Pp. 47-72. (In Russ.)

Nedyalkov V. P. Causativity and passivity: ties revisited. In: [Bashkir State University: Scholarly Notes]. XXI, ser. 'Philological Sciences'. Ufa, 1964. Vol. 9. Pp. 301-310. (In Russ.)

Nedyalkov V. P., Silnitsky G. G. Typology of morphological and lexical causatives. In: [Typology of Causative Constructions]. Leningrad: Nauka, 1969. 311 p. (In Russ.)

Oskolskaya S. A. Plurality of participants in the Kalmyk language: verb indicators revisited. Acta Linguistica Petropolitana. 2009. Vol. 5. No. 2. Pp. 310-346. (In Russ.)

Sanzheev G. D. [Comparative Grammar of Mongolic Languages: Verb]. Moscow: Nauka, 1963. 266 p. (In Russ.)

Sanzheev G. D. [Modern Mongolian]. Moscow: Vostochnaya Literatura, 1960. 104 p. (In Russ.)

Shibatani M., Pardeshi P. The causative continuum // The Grammar of Causation and Interpersonal Manipulation [Typological Studies in Language]. Vol. 48. Masayoshi Shibatani (ed.), Amsterdam: John Benjamins, 2002. Pp. 85126. (In Eng.) 